\title{
Action-specific Cognitions of Planned and Preparatory Behaviors of Condom Use among Dutch Adolescents
}

\author{
Pepijn van Empelen · Gerjo Kok
}

Received: 13 January 2006/Revised: 23 March 2007 / Accepted: 1 September 2007/Published online: 10 January 2008

(C) The Author(s) 2008

\begin{abstract}
Many adolescents fail to use condoms, even when they are motivated to do so. An important reason for their failure to use condoms is that they do not prepare themselves for potential sexual encounters. The present study examined the circumstances under which Dutch adolescents were likely to prepare themselves for condom use (buying and carrying). In a sample of 399 secondary school students, including students with and without sexual experience, it was found that intended condom use was not sufficient to ensure that adolescents plan and prepare for condom use. It was found that having the goal of condom use did not necessarily result in preparatory behavior, such as condom buying and condom carrying. The data showed that action-specific social-cognitive factors of preparatory behavior explained preparatory behavior, beyond the decision to use condoms. This suggests that interventions aimed at promoting condom use should focus not only on condom use itself, but should also motivate and encourage adolescents to buy and carry condoms.
\end{abstract}

Keywords Adolescents · Condom use · Preparatory action · Action-specific cognitions . Planned behavior

P. van Empelen $(\bowtie)$

Institute for Psychological Research, Department of Clinical, Health and Neuropsychology, Leiden University, P.O. Box 9555, 2300 RB Leiden, The Netherlands

e-mail: P.vanEmpelen@fsw.LeidenUniv.nl

G. Kok

Department of Work and Social Psychology, Maastricht University, Maastricht, The Netherlands

\section{Introduction}

Sexually transmitted infections (STIs) pose a serious threat to adolescents, with a disproportionate number of adolescents being infected with STIs, especially chlamydia (CDC, 2005; Van de Laar, de Boer, Koedijk, \& Op de Coul, 2005). Adolescents are more at risk because they tend to have a higher number of partners and more concurrent partnerships than older age groups. Consequently, considerable efforts have been made to promote safer sexual behavior among youths (Schaalma, Abraham, Gillmore, \& Kok, 2004). Many of these interventions have been derived from social-cognitive models (e.g., Theory of Planned Behavior, Ajzen, 1991; Social Cognitive Theory, Bandura, 1997). The main assumption of these models is that behavior change can be established by creating a change in intentions (for a recent meta-analysis, see Webb \& Sheeran, 2006). Intention is seen as an indication of a person's readiness to perform a given behavior, and it is considered to be the most immediate antecedent of behavior. Intentions can be seen as behavioral dispositions until, at an appropriate time and opportunity, they are translated into action (Ajzen, 1988).

Interventions have been effective in motivating adolescents to engage in safer sex, but most interventions fail to effect change at the behavioral level (Kirby, 2002; Vanwesenbeeck et al., 2003). Many adolescents report that they are motivated/intending to use condoms, but in practice often fail to act in accordance with their intentions. In line with this, one out of four Dutch adolescents reports having had unprotected sex (no condom and no contraceptive pill) at first intercourse, and one out of six reports having had unprotected sexual intercourse at last intercourse (Vanwesenbeeck et al., 2003). In particular, adolescents may be unprepared for casual sexual encounters (e.g., "hook-ups"; cf. Paul, McManus, \& Hayes, 2000). For instance, it has been shown that young people may have sexual contacts while on holiday, 
without necessarily having planned it (Bakker \& Vanwesenbeeck, 2002). Hence, casual sex may not be anticipated or intended, but young people may be willing to respond to that opportunity (cf. Gibbons, Gerrard, \& Lane, 2003). Indeed, Gibbons, Gerrard, Blanton, and Russell (1998) suggested that in the context of complex behaviors, many adolescents engage in risk behaviors without actually having intended to do so (i.e., "it just happened"). It has been shown that "in the heat of the moment" sexual decision making is to a great extent influenced by the motive to have sex, rather than the motivation to protect oneself against unwanted pregnancy or sexually transmitted infections (Abraham et al., 1999; Ariely \& Loewenstein, 2006).

Thus, adolescents are likely to engage in unprotected sexual practices, despite having safer sex intentions, simply because they are unprepared for the sexual encounter. That preparation is an important prerequisite for safer sex, more specifically condom use, among adolescents has been demonstrated by Bryan, Fisher, and Fisher (2002) and van Empelen and Kok (2006). Adolescents who intended to use condoms and prepared to do so (buying, carrying, and communicating) were more likely to actually use condoms. In the study by van Empelen and Kok (2006), however, adolescents seemed to prepare themselves only in the context of steady sexual relationships. In the context of casual sex, condom use was not guided by preparatory actions. The latter suggests that adolescents rarely prepare themselves for unexpected sexual encounters and, as such, whether or not they use condoms may depend largely on the context in which the encounter takes place.

In conclusion, there are multiple behaviors (including buying and carrying condoms) which underlie the goal of condom use, and it seems vital to address each of these behaviors when aiming at the promotion of condom use. Specifically, for the promotion of condom use it seems important to ensure that adolescents are prepared for condom use, regardless of being sexually active or not, given the unexpectedness of possible sexual encounters.

In acknowledging that condom use is not a single behavior but rather a behavioral category, Fishbein (1993) suggested that it is necessary to examine motivational processes for all specific behaviors that may enhance the likelihood of attaining that behavioral category. As such, it is predicted that the goal of safer sex or condom use is not sufficient in explaining preparatory behaviors, but rather action-specific cognitions are important in explaining specific preparatory behaviors (cf. Abraham, Sheeran, \& Johnston, 1998; Bryan et al., 2002).

Partial support for the notion of examining actionspecific cognitions rather than goal-related cognitions was provided by Conner and Norman (1996), who showed that sub-behaviors of weight loss (e.g., avoiding fat intake versus exercising) were differently affected by attitudes and perceived control. In addition, Schaalma, Kok, and Peters (1993) showed that adolescents with sexual experience expressed fewer difficulties with raising the subject of condom use, but felt less capable of ensuring condom use (see also Schwarzer \& Renner, 2000, who make a distinction between action self-efficacy and coping self-efficacy). In addition, differences in social-cognitive antecedents have been found for taking and obtaining ecstasy (Orbell, Blair, Sherlock, \& Conner, 2001) and using condoms versus raising the subject of condom use (Yzer, Siero, \& Buunk, 2001).

Thus, it seems important to specify not only preparatory behaviors of the desired healthy behaviors, but also actionspecific cognitions that may facilitate or inhibit each of the preparatory behaviors (Abraham \& Sheeran, 2003b; Abraham et al., 1998; Bartholomew, Parcel, Kok, \& Gottlieb, 2006; Bryan et al., 2002; Kok, Schaalma, Ruiter, van Empelen, \& Brug, 2004) (see Fig. 1).

\section{The Present Study}

The present study aimed at examining action-specific cognitions of intended condom use and preparatory actions in the context of condom use among Dutch adolescents. We contend that, in order to ensure actual use of condoms, it is essential that adolescents prepare themselves for possible sexual encounters by buying and carrying condoms. Concurring with various social-cognitive theories (for an integrated model, see Abraham et al., 1998), we assert that it is crucial to understand the social-cognitive factors that motivate adolescents to use condoms. Based on the preceding discussion, however, we expect that having a goal intention to use condoms does not suffice to ensure the initiation of preparatory actions. Consequently, we predict that in addition to having a positive goal intention to use condoms, action-specific cognitions and corresponding behavioral intentions are necessary to ensure that adolescents engage in preparatory actions.

As shown in Fig. 1, we expect that preceding preparatory behaviors may enhance the initiation of succeeding (preparatory) actions, although as argued, a focus on actions in

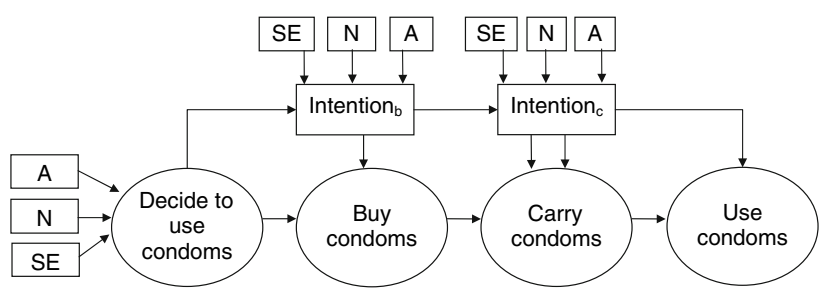

Fig. 1 Schematic overview of antecedents of preparatory behaviors of condom use. $\mathrm{SE}=$ self-efficacy, $\mathrm{N}=$ normative concepts, $\mathrm{A}=$ attitudinal concepts. It should be noted that preparatory behaviors may sequentially and directly influence condom use 
itself is not sufficient for predicting succeeding stages. Finally, it should be pointed out that, although there is a logical sequence in actions, they do not necessarily all need to be followed. For instance, when a girl is motivated to use condoms and her boyfriend has condoms available and suggests using them, they are very likely to engage in safer sex. Figure 1 gives an overview of the present study and the possible sequence of actions that need to be taken for condom use and their social-cognitive prerequisites.

For the present study, we took into account social-cognitive concepts derived from a theoretical review of Abraham et al. (1998). The review highlights the importance of the concepts specified in the Theory of Planned Behavior (TPB, Ajzen, 1991): attitudes, injunctive norms, self-efficacy, and intentions. In addition, Abraham et al. (1998) suggest adding some additional concepts to deal with some of the shortcomings of the ТPB. ${ }^{1}$ First, they suggested differentiating between injunctive norms (the perceived approval by others of certain behavior) and descriptive norms (a person's perception of what others do). Descriptive norms have found to be important in the context of safer sex (Schaalma et al., 1993; White, Terry, \& Hogg, 1994). In addition, we assessed personal norms and anticipated regret for condom use with steady and casual sex partners, as well as for condom carrying. Personal norms are defined as personal behavioral standards of what is right or ideal. Personal norms have been shown to be important in the context of safer sex (van Empelen, Kok, Jansen, \& Hoebe, 2001; van Kesteren, Hospers, van Empelen, van Breukelen, \& Kok, 2007).

Furthermore, anticipated affect for condom use and condom carrying was examined. The assumption underlying the predictive value of anticipated regret is that people who are more likely to anticipate on the negative affective consequences of unsafe sexual behavior, before having actual sexual intercourse, might be influenced by these negative feelings and therefore decide to use condoms. Anticipated affect has been found to be important in explaining condom use in adolescents and other populations (Richard, Van der Pligt, \& De Vries, 1995; van Empelen, Kok, et al., 2001). Perugini and Bagozzi (2001) have suggested that not only the anticipation of negative affect may be an important contributor to explaining health behavior, but also anticipated positive emotions. Therefore, within the present context, both negative and positive emotions were assessed. Anticipated affect is assumed to fill in some of the gaps of the TPB, given that the TPB has been referred to as a rather reasoned, cognitive model (e.g., Gibbons et al., 2003).

Finally, we included a specific habit measure for each behavior (condom use with steady and casual sex partners, condom buying, and condom carrying). Habit is considered

\footnotetext{
1 According to Ajzen (1991), other cognitions can be added to the TPB when they enhance the prediction of behavior.
}

to be important in explaining frequent behavior (Ouellette \& Wood, 1998). It is assumed that once behavior becomes habit, people may engage in that behavior without being very conscious of it and, as such, cognitions may play a less important role among adolescents who frequently engage in preparatory behaviors (van Empelen \& Kok, 2006; Yzer et al., 2001).

Additionally, experience with sexual intercourse or condom use may have an impact on the predictors mentioned (Schaalma et al., 1993), as well as preparatory actions. As such, it is important to identify whether differences exist between experienced and non-experienced students. It should be noticed that even when being sexually inexperienced, adolescents may hold beliefs about condom use and preparatory actions, including, for instance, ideas about condoms use being embarrassing or condoms being useful (Schaalma et al., 1993).

To summarize, in the present study we examined intended condom use (with steady and casual sex partners) ${ }^{2}$ and intended and actual buying and carrying of condoms by adolescents, taking into account action-specific cognitions and controlling for preceding (intended) preparatory behavior.

\section{Method}

\section{Participants}

Participants were students in the final 2 years of pre-vocational secondary education (in Dutch: VMBO) from eight schools in various locations throughout the Netherlands. The majority of the participants in the studied sample were male $(53.6 \%)$ and reported their sexual orientation as heterosexual (95.4\%). The participants were Dutch (49.1\%), Surinamese (15.3\%), Moroccan (8.5\%), Turkish (8.8\%), or other ethnic backgrounds (19.3\%), and had a mean age of 15 years $(S D=.88)$.

\section{Procedure}

The participating schools were located in major cities (e.g., Amsterdam, Rotterdam) and middle-sized cities (e.g., Haarlem, Eindhoven). The schools were chosen at random, selecting random numbers from the school catalogue of the online Dutch phonebook. A total of 21 schools were approached, of which eight agreed to participate in the study. The most

\footnotetext{
${ }^{2}$ It has been shown that the frequency of condom use differs with regard to casual and steady sex partners within various populations. It has also been shown that determinants may differ in relation to partner status (i.e., steady or casual partner) (Fortenberry, Tu, Harezlak, Katz, \& Orr, 2002; Morrison, Baker, \& Gillmore, 2000; van Empelen, Kok, et al., 2001; van Empelen, Schaalma, Kok, \& Jansen, 2001).
} 
common reason for declining participation was ongoing participation in other studies. Another reason was the inability to make an appointment. The number of participants per participating school varied from 26 students (a school in Eindhoven) to 140 students (a school in Rotterdam).

Permission was granted by the schools and, in addition, a letter was sent to the parents explaining the purpose of the study and the possibility to refuse participation. Additionally, students were explained that the study topic was on sexuality, HIV, and STIs. Students were informed that participation was on a voluntary basis and that they could quit at any time, without having to state a specific reason. All students received a gift coupon of 5 euro for their participation.

Following a prospective design, participants completed baseline self-administered questionnaires with several predictor and behavioral variables and at a 3-month follow-up with behavioral measures. A total of 399 participants completed both questionnaires (81.6\% of the 489 participants at baseline). A subset of the sample (the sexual active sample) was examined in a separate study, in which the relationship between preparatory behaviors and actual condom use was examined (van Empelen \& Kok, 2006). Within the present study, drop-out largely could be explained due to the inability to match questionnaires or by absenteeism of students. It is reported that, on average, $8 \%$ of Dutch secondary school students are absent on an average day (NIPO, 2002). In order to ensure confidentiality, questionnaires were not labeled, but matched on school characteristics, demographic information, and the initial of parents. Consequently, some questionnaires could not be matched $(8.5 \%)$.

\section{Measures}

At baseline, all social-cognitive predictors that were specified for each preparatory behavior (buying, carrying) and the goal behavior (condom use) were measured. At the post-test, all preparatory behaviors of condom use (buying and carrying condoms) were measured. Measures were derived from the literature, as well as from individual interviews with Dutch adolescents (van Empelen \& Kok, 2005).

\section{Background Variables (T1)}

Number of Partners. Number of partners was assessed by asking participants to indicate whether they had ever had sexual intercourse; those participants who indicated experience with sexual intercourse were asked to report the number of partners. Because the number of partners was highly skewed, partner frequency was divided into four categories: no sex partners $(63.7 \%)$; one partner $(11.7 \%)$; two partners $(8.4 \%)$; three or more partners $(16.2 \%)$. These numbers were comparable to a large scale representative study among Dutch adolescents (de Graaf, Meijer, Poelman, \& Vanwesenbeeck, 2005).

Intentional Abstinence. Intentional abstinence was measured by asking participants their reasons for not having had sex. Participants could indicate four categories, namely "it just hasn't happened yet"; "I wait until I am older"; "I wait until I am married," and "other reason." The latter option was an open-ended response. Waiting until being older or married was defined as intentional abstinence; other reasons (e.g., "it just hasn't happened yet") were excluded from the intentional abstinence category.

\section{Proximal Measures}

Attitude-related Concepts. Attitudes were assessed for each preparatory behavior (buying, carrying) and condom use (separately for steady and casual partners) by means of four 7-point semantic differentials (good-bad; useful-useless; pleasant-unpleasant; unimportant-important). Cronbach's alphas were: .64 (buying), .60 (condom use with casual sex partner), .82 (carrying), and .84 (condom use with steady partner), respectively.

Anticipated affect was measured by asking people how they would feel after a specific situation (cf. Richard et al., 1995; e.g., "having sex with a steady sex partner without using a condom"; "wanting to have sexual intercourse, but not having condoms available"). Affect was measured with five 7-point items, ranging from "not at all" to "very much" (cf. Bagozzi, Dholakia, \& Basuroy, 2003, regret, frustration, satisfaction (reverse coded), relief (reverse coded), and fear). Cronbach's alphas were: .86 (steady), .84 (casual), and 61 (condom carrying), respectively. Anticipated affect was measured after intentions because it has been shown that measuring anticipated affect before intentions influences responses on the intentions scale (Abraham \& Sheeran, 2003a).

Norms. Injunctive norms were measured for buying, carrying, condom use with steady sex partners, and condom use with casual sex partners by means of four 5-point items (except for carrying, 3 items), ranging from "certainly not" to "certainly." Items were related to normative beliefs regarding best friends, other friends, parents, and other family members. Cronbach's alphas ranged from .83 (buy) to .90 (condom use with steady partners).

Descriptive norms were measured for condom use with steady and casual sex, buying, and carrying condoms by means of single items (e.g., "My best friends always have condoms available"). The scale ranged from "certainly not" to "certainly."

Personal normative beliefs were measured for using condoms (with steady or casual sex partners) and condom 
carrying by means of four 5-point items (ranging from "totally disagree" to "totally agree"). Example items were: "I see myself as a person who always should have condoms available"; "It is my principle to always use condoms with my steady partner" (measures derived from Conner \& Flesch, 2001; Terry, Hogg, \& White, 1999). Cronbach's alphas ranged from .85 (condom use with casual sex partners) to .90 (condom use with steady sex partners).

Self-efficacy. Self-efficacy was measured for each behavior (condom use with steady partners, casual sex partners, buying, and carrying). Self-efficacy in regard to using condoms with casual and steady sex partners was measured with eight and nine items (e.g., Dilorio, Maibach, O'Leary, Sanderson, \& Celentano, 1997; Morrison, Baker, \& Gillmore, 2000; Schaalma et al., 1993), respectively ("I feel capable of using condoms [with a steady partner], even when I am sexually aroused"). One item measured self-efficacy to buy condoms, and two items measured self-efficacy to carry condoms ("I feel capable of carrying condoms with me, even when there is no specific occasion for doing so"). Responses ranged from 1 to 5 ("certainly not" to "certainly"). Cronbach's alphas range from .69 to .92 .

Intention. Intentions were measured with regard to the use of condoms (casual and steady partners), condom buying, and carrying (cf. Bryan et al., 2002). Each behavior was assessed with two items. Example items included: "I intend to buy condoms in the next three months" and "I will buy condoms in the next three months" Responses ranged from 1 to 5 ("certainly not" to "certainly"). The reliability of the scales ranged between .81 (use with casual sex partners) to .91 (buying condoms).

Habit. Habitual behavior was assessed using an abbreviated version of the habit index of Verplanken and Orbell (2003). For each behavior (condom use with steady and casual sex partners, buying, carrying), we measured whether the behavior was performed routinely ("I buy condoms routinely") and automatically ("I carry condoms without having to consciously remember"). For the preparatory behaviors, we included the frequency of the behavior. ${ }^{3}$ Cronbach's alphas ranged from .68 to .90 .

Preparatory Behaviors (T2). Preparatory behaviors (buying, carrying) were measured at post-test, by asking how often the participants had bought condoms in the last 6 months and had carried condoms in the last 6 months. Participants responded on a 5-point scale, ranging from "never" to "always."

\footnotetext{
${ }^{3}$ Because not every young person is sexually active or habitually sexually active, the frequency of condom use does not seem to be a good proxy for habitual use (see also Ajzen, 2002, about the inappropriateness of a frequency measure to gauge infrequently performed behaviors). We included the frequency measure for buying and carrying condoms, as these behaviors (especially carrying) can be performed routinely, irrespective of sexual experience.
}

Data Analysis

Regression analyses were applied to identify the relationship between social-cognitive constructs and preparatory behaviors of condom use. First, we examined the relationship between social-cognitive constructs and intended (preparatory) behavior. Second, we examined the relationship between social-cognitive constructs and actual preparatory behaviors.

To test the relationship between variables and intentions, we conducted a series of hierarchical regression analyses. In the first step, we treated number of sex partners and intentional abstinence as covariates to control for possible differences in the multivariate analyses resulting from differences in sexual experience (Van der Straten, Catania, \& Pollack, 1998). Intentional abstinence was controlled for, given that adolescents may have chosen the abstinence strategy over the strategy of condom use, may perceive sexual intercourse as less likely to happen in the short-term future. In the second step, we entered preceding intentions and/or preparatory behaviors when applicable (see Fig. 1 for the sequence of actions). In the third step, we entered the TPB variables. In the fourth step, we entered additional variables that had been specified and were imbedded in the motivational model of Abraham et al. (1998) as important contributors to the TPB. In the fifth step we entered habit. Finally, using a forward entry method, we investigated whether other background variables or demographics were important. These factors were age, sex, and ethnicity.

\section{Results}

\section{Descriptive Analyses}

Of the 399 participants, 146 reported having ever been sexually active at T1 (information for two participants was missing). Older participants were more likely to be sexually experienced than younger participants ( $M$ age 15.4 vs. 14.9, $t(295)=5.35<.001)$. Forty-one $(34.5 \%)$ of the sexually active students reported having a steady sexual relationship at the time of the survey and $88.0 \%$ of the sexually active students had had sex with a casual sex partner in the last year. Of those who reported having a steady sex partner at baseline, $56.4 \%$ reported to have always used condoms. For those who reported having had sex with a casual sex partner in the past year, $60.2 \%$ always used condoms. The majority reported that they had never bought $(78 \%)$ or carried (59.2\%) condoms (T2). More specifically when comparing sexually active and inactive students, 91.2\% (of 251) of those without sexually experience never had bought condoms versus $46.6 \%$ (of 146) adolescents with sexual experience. For condom carrying, these differences were $79.3 \%$ and $26.7 \%$, respectively. Participants who carried condoms regularly also 
bought condoms more often, whereas those who seldom carried condoms had not bought condoms themselves. The number of participants who carried condoms at all times was very low $(7.8 \%)$.

\section{Deciding to Use Condoms}

Before engaging in any preparatory actions of condom use, a person must feel motivated and committed to actually use condoms. As such, we first examined the possible predictors that might increase the likelihood that adolescents would decide to have protected sexual intercourse, taking into account partner status. In general, adolescents were less positive about condom use with steady than with casual sex partners. Paired $t$-tests revealed that all predictors of condom use with casual sex partners were more positive (all $t \mathrm{~s}>2.99, p<.005)$ than for condom use with steady partners (see Table 1), with the exception of self-efficacy, which did not differ on the basis of partner status, $t(383)<1$, ns.

\section{Steady Sex Partners}

In order to identify possible predictors of intended condom use with steady partners, we first examined the means and zero-order correlations between predictors and intentions (see Table 1). The means showed that attitudes and norms were generally positive, with the exception of descriptive norms, which were generally moderate, indicating that participants were generally unaware of their friends' tendency to use condoms with steady sex partners. Actual sexual experience was limited and, as such, the relationship between habit and other social-cognitive factors was low. Furthermore, in general, the TPB variables showed medium to high correlations.

Second, we examined the contribution of predictors in explaining intended condom use with steady partners (see Table 2). In the first step, intention was regressed on the number of sex partners and intentional abstinence, which resulted in a non-significant model, with an explained variance of less than $3 \%$. A higher number of sex partners in the past was related to a diminished intention to use condoms with steady partners (see Table 2). In the second step, the TPB variables were added, which resulted in an increased explained variance of $55 \%(p<.001)$, with injunctive norms and self-efficacy to use condoms, as predictors of intended condom use with steady partners. The additional steps revealed an increase in explained variance, with the descriptive norm being an important predictor. The final model explained 59\% of variance in intended condom use with steady partners.

\section{Casual Sex Partners}

Means and zero-order correlations revealed that, in general, participants had a very positive attitude toward condom use and they anticipated negative affect of unprotected sexual intercourse within the context of casual sex (see Table 1). Within this context, motivation to have protected sex appeared largely based on what was considered morally right or what they believed they ought to do. Interestingly, there was a strong correlation between their perceived capabilities to practice safer sex (i.e., self-efficacy) and personal norms.

As was the case for steady sex partners, the hierarchical regression of intended condom use with casual sex partners revealed that number of partners and intentional abstinence did not explain any significant variance in condom use. In the second step, the TPB variables explained an additional $53 \%$ variance in intended condom use, with injunctive norms and self-efficacy the strongest predictors. Taking into account the additional concepts in Step 3, the data indicated that, within the context of casual sex, adolescents were primarily driven by feelings of what was the right thing to do (i.e., personal norms, anticipated affect, but also injunctive norms). The final model explained 59\% of variance in intended condom use with casual sex partners.

\section{Buying Condoms}

When examining descriptive analyses of condom buying, the results revealed that adolescents lack self-efficacy to buy condoms, as well as a strong intention to buy condoms (see Table 1).

Next, we examined the relationships between (intended) condom buying and possible predictors. First, the relationship between intended condom use ${ }^{4}$ and intended buying of condoms was examined, assuming that intended condom use is a prerequisite for (intended) condom buying. Second, we examined specific cognitive factors related to buying condoms. For condom buying, we focused on the TPB variables and descriptive norms. Personal norms and anticipated affect were not assessed. The zero-order correlations showed that the TPB variables and descriptive norms were interrelated. Interestingly, intended condom use was positively related to an increased motivation to buy condoms, but was unrelated to the actual buying of condoms (see Table 3 ).

\footnotetext{
${ }^{4}$ Intended condom use with casual sex partners and steady sex partners was combined into one variable, i.e., intended condom use $(r=.85)$.
} 
Table 1 Correlations between action-specific cognitions, intended condom use and preparatory actions $(N=399)$

\begin{tabular}{|c|c|c|c|c|c|c|c|c|c|c|}
\hline & $M$ & Range & I & Att & Sn & $\mathrm{Se}$ & Dn & $\mathrm{H}$ & Pn & $\mathrm{Aa}$ \\
\hline \multicolumn{11}{|c|}{ Condom use with steady partners } \\
\hline Intention & 3.75 & $1-5$ & - & & & & & & & \\
\hline Attitude & 5.14 & $1-7$ & .394 & - & & & & & & \\
\hline Injunctive norm & 3.63 & $1-5$ & .577 & .386 & - & & & & & \\
\hline Self-efficacy & 3.85 & $1-5$ & .688 & .348 & .477 & - & & & & \\
\hline Descriptive norm & 3.19 & $1-5$ & .476 & .326 & .542 & .413 & - & & & \\
\hline Habit & 2.16 & $1-5$ & .190 & $.067 \mathrm{~ns}$ & .148 & .185 & .066 & - & & \\
\hline Personal norm & 3.58 & $1-5$ & .503 & .596 & .500 & .452 & .402 & .091 & - & \\
\hline Anticipated affect & 4.46 & $1-7$ & .358 & .435 & .316 & .304 & .317 & -.106 & .487 & - \\
\hline \multicolumn{11}{|c|}{ Condom use with casual partners } \\
\hline Intention & 3.95 & $1-5$ & - & & & & & & & \\
\hline Attitude & 6.09 & $1-7$ & .268 & - & & & & & & \\
\hline Injunctive norm & 3.93 & $1-5$ & .608 & .306 & - & & & & & \\
\hline Self-efficacy & 3.87 & $1-5$ & .663 & .284 & .538 & - & & & & \\
\hline Descriptive norm & 3.64 & $1-5$ & .393 & .198 & .460 & .356 & - & & & \\
\hline Habit & 1.76 & $1-5$ & .115 & .139 & .196 & .191 & .179 & - & & \\
\hline Personal norm & 3.64 & $1-5$ & .548 & .355 & .380 & .490 & .313 & .127 & - & \\
\hline Anticipated affect & 5.00 & $1-7$ & .395 & .190 & .322 & .343 & .166 & $-.018 \mathrm{~ns}$ & .369 & - \\
\hline \multicolumn{11}{|l|}{ Condom buying } \\
\hline Intention & 2.78 & $1-5$ & - & & & & & & & \\
\hline Attitude & 5.67 & $1-7$ & .256 & - & & & & & & \\
\hline Injunctive norm & 3.05 & $1-5$ & .390 & .317 & - & & & & & \\
\hline Self-efficacy & 2.74 & $1-5$ & .332 & .305 & .441 & - & & & & \\
\hline Descriptive norm & 1.51 & $1-5$ & .231 & .173 & .308 & .263 & - & & & \\
\hline Habit & 2.80 & $1-5$ & .346 & .152 & .222 & .328 & .272 & - & & \\
\hline \multicolumn{11}{|l|}{ Condom carrying } \\
\hline Intention & 2.69 & $1-5$ & - & & & & & & & \\
\hline Attitude & 4.86 & $1-7$ & .382 & - & & & & & & \\
\hline Injunctive norm & 2.95 & $1-5$ & .444 & .389 & - & & & & & \\
\hline Self-efficacy & 3.66 & $1-5$ & .355 & .363 & .402 & - & & & & \\
\hline Descriptive norm & 2.54 & $1-5$ & .351 & .280 & .430 & .353 & - & & & \\
\hline Habit & 1.81 & $1-5$ & .468 & .434 & .357 & .388 & .377 & - & & \\
\hline Personal norm & 2.75 & $1-5$ & .226 & .200 & .236 & .098 & .118 & $.047 \mathrm{~ns}$ & - & \\
\hline Anticipated affect & 4.48 & $1-7$ & $-.062 \mathrm{~ns}$ & $.022 \mathrm{~ns}$ & $.077 \mathrm{~ns}$ & $.044 \mathrm{~ns}$ & $-.036 \mathrm{~ns}$ & -.103 & $.029 \mathrm{~ns}$ & - \\
\hline
\end{tabular}

Note: $\mathrm{ns}=$ non-significant, all other relationships are significant $(p<.05) . \mathrm{I}=$ intention; Att $=$ Attitude; Sn $=$ injunctive norm; Se $=$ selfefficacy; $\mathrm{Dn}=$ descriptive norm; $\mathrm{H}=$ habit $\mathrm{Pn}=$ Personal norm; $\mathrm{Aa}=$ Anticipated affect

\section{Intention}

The initial step of the hierarchical regression of intended condom buying revealed that number of partners and intentional abstinence were related to intended condom buying (see Table 3). Past number of sex partners was related to a more positive intention to buy condoms, whereas intentional abstinence was related to a lower intention to buy condoms. In the second step, intended condom use explained an approximate $13 \%$ of the variance in intended condom buying. In the additional steps, the TPB variables, descriptive norms, habit and background variables were entered, with injunctive norms and habits explaining additional variance. The final model explained $32 \%$, with having had three or more sex partners in the past, a positive intention towards condom use, a positive injunctive condom buying norm, and the habit of buying condoms explaining intended condom buying.

\section{Behavior}

Actual condom buying could be explained by the number of past sex partners and intentional abstinence. In the second 
Table 2 Regression analyses of intended condom use on condom use cognitions, separated for steady and casual sex partners $(N=399)$

\begin{tabular}{|c|c|c|c|c|}
\hline & $r$ & Initial Model $\beta$ & Final Model $\beta$ & $\Delta R^{2}$ \\
\hline \multicolumn{5}{|l|}{ Steady sex partners } \\
\hline Step 1 & & & & .026 \\
\hline \multicolumn{5}{|l|}{ \# of partners (referent: none) } \\
\hline One & .087 & .046 & -.010 & \\
\hline Two & .021 & -.007 & -.041 & \\
\hline Three or more & -.132 & $-.145^{*}$ & -.050 & \\
\hline Intentional abstinence & -.038 & -.070 & -.060 & \\
\hline Step 2-TPB variables & & & & $.541 * * *$ \\
\hline Attitudes & .394 & $.104 *$ & .031 & \\
\hline Injunctive norm & .577 & $.283^{* * *}$ & $.210 * * *$ & \\
\hline Self-efficacy & 688 & $.513 * * *$ & $.462 * * *$ & \\
\hline Step 3-Additional concepts & & & & $.017 * *$ \\
\hline Descriptive norm & .476 & $.094 *$ & $.092 *$ & \\
\hline Personal norm & .503 & .093 & .088 & \\
\hline Anticipated regret & .358 & .068 & .075 & \\
\hline Step 4 & & & & .003 \\
\hline Habit & .190 & .071 & .071 & \\
\hline Step 5-Background variables & & - & - & - \\
\hline Total $R^{2}$ & & & & .586 \\
\hline \multicolumn{5}{|l|}{ Casual sex partners } \\
\hline Step 1 & & & & .017 \\
\hline \multicolumn{5}{|l|}{ \# of partners (referent: none) } \\
\hline One & .105 & .089 & .040 & \\
\hline Two & .020 & .015 & .001 & \\
\hline Three or more & -.086 & -.076 & .004 & \\
\hline Intentional abstinence & -.026 & -.023 & -.028 & \\
\hline Step 2-TPB variables & & & & $.516 * * *$ \\
\hline Attitudes & .268 & .022 & -.026 & \\
\hline Injunctive norm & .608 & $.351 * * *$ & $.279 * * *$ & \\
\hline Self-efficacy & .663 & $.463 * * *$ & $.363 * * *$ & \\
\hline Step 3-Additional concepts & & & & $.052 * * *$ \\
\hline Descriptive norm & .393 & .051 & .056 & \\
\hline Personal norm & .548 & $.226 * * *$ & $.229 * * *$ & \\
\hline Anticipated regret & .395 & $.099 *$ & $.098 *$ & \\
\hline Step 4 & & & & .003 \\
\hline Habit & .115 & -.058 & -.058 & \\
\hline Step 5-Background variables & - & - & - & - \\
\hline Total $R^{2}$ & & & & .586 \\
\hline
\end{tabular}

step, intended condom use and intended condom buying were entered, with only intended condom buying predicting actual condom buying. The relationship between intentional abstinence and actual condom buying was no longer significant, after the inclusion of intended condom buying, suggesting that the effect was mediated by intention to buy condoms (Sobel's $z=3.31, p<.001$ ). The third step, entering the TPB variables, did not result in an improved model. The fourth step showed an significant increase in the explained variance, with descriptive norms positively related to actual condom buying. When habit was entered in step five, intention to buy condoms was no longer a significant predictor of condom use, whereas habit was the most important predictor. Finally, background variables were entered in the last step, with sex being a significant predictor of buying condoms: females were less likely to buy condoms. Age was also found to be a significant predictor, while the zero-order correlations were non-significant, indicating a negative classical suppressor effect (Tabachnik \& Fidell, 1996). Further examination revealed that age reduced some 
Table 3 Regression analyses of intended and actual condom buying on intended condom use and condom buying cognitions $(N=399)$

\begin{tabular}{|c|c|c|c|c|c|c|c|c|}
\hline & \multicolumn{4}{|c|}{ Intended condom buying } & \multicolumn{4}{|c|}{ Actual condom buying (T2) } \\
\hline & $r$ & Initial Model $\beta$ & Final Model $\beta$ & $\Delta R^{2}$ & $r$ & Initial Model $\beta$ & Final Model $\beta$ & $\Delta R^{2}$ \\
\hline Step 1 & & & & $.111 * * *$ & & & & $.138 * * *$ \\
\hline \multicolumn{9}{|l|}{ \# of partners (referent: none) } \\
\hline One & .053 & .034 & -.014 & & .053 & .082 & .034 & \\
\hline Two & .114 & .093 & .061 & & .038 & .065 & .039 & \\
\hline Three or more & .199 & $.152 * *$ & $.123 *$ & & .326 & $.313 * * *$ & $.213 * * *$ & \\
\hline Intentional abstinence & -.299 & $-.230 * *$ & $-.133^{*}$ & & -.243 & $-.122^{*}$ & -.006 & \\
\hline Step 2 & & & & $.132 * * *$ & & & & $.024 *$ \\
\hline Intention to use condoms & .343 & $.368 * * *$ & $.254 * * *$ & & .035 & .014 & -.022 & \\
\hline Intention to buy & - & - & - & & .256 & $.158^{* *}$ & .080 & \\
\hline Step 3-TPB variables & & & & $.054 * * *$ & & & & .004 \\
\hline Attitudes & .256 & .083 & .066 & & .074 & .022 & -.015 & \\
\hline Injunctive norm & .390 & $.192 * * *$ & $.177 * *$ & & .171 & .065 & .029 & \\
\hline Self-efficacy & .332 & .068 & .051 & & .140 & .008 & -.053 & \\
\hline Step 4-Additional variables & & & & & & & & $.020 * *$ \\
\hline Descriptive norm & .231 & .026 & .003 & .001 & .240 & $.157 * *$ & $.111^{*}$ & \\
\hline Step 4 & & & & & & & & $.059 * * *$ \\
\hline Habit & .346 & $.177 * *$ & $.177 * *$ & $.022 * *$ & .429 & $.292 * * *$ & $.267 * *$ & \\
\hline Step 5-Background variables & & - & - & - & & & & $.030 * *$ \\
\hline Sex (referent: male) & & & & & -.287 & $-.160 * *$ & $-.149 * *$ & \\
\hline Age & & & & & .023 & $-.105^{*}$ & $-.105^{*, \mathrm{a}}$ & \\
\hline Total $R^{2}$ & & & & .320 & & & & .276 \\
\hline
\end{tabular}

Note: $* p<.05, * * p<.01, * * * p<.001$

${ }^{\text {a }}$ Suppressor effect

of the error variance in number of partners, as age was related to the number of sex partners. The overall model explained $28 \%$ of variance in condom buying behavior.

\section{Carrying Condoms}

Next, we examined condom carrying. The means showed that, on average, adolescents hesitated to carry condoms (which is represented by intention, see Table 1), and did not feel explicit social approval to carry them. In addition, they were less positive about carrying condoms than buying or using them. In contrast to condom buying, adolescents, on average, expressed a higher self-efficacy to carry condoms. The inter-correlations showed that anticipated affect was not related to an enhanced intention or actual condom availability. A very strong correlation, on the other hand, was found for intended condom buying and intended condom carrying ( $r=.79$, see Table 4$)$.

\section{Intention}

Intended condom carrying was explained by the number of past sex partners and intentional abstinence, but, as in the case of buying condoms, these factors were mediated by intended condom buying (see Table 4). The second step of the hierarchical regression analysis explained $53 \%$ of the variance in intended condom use, with intended buying a very strong predictor of intended carrying. Additional analysis showed that intention to use condoms was mediated by intended condom buying (Sobel's $z=7.53, p<.001$ ). The third step of the regression analysis showed that the TPB variables related to condom carrying explained additional variance over and above preparatory actions, with attitudes and injunctive norms positively related to intended condom carrying (see Table 4). In addition, descriptive norms also explained additional variance. The positive beta weight between anticipated regret and intended condom carrying suggests a suppressor effect, as the zero-order correlation was non-significant.

The final model, with the addition of habit in the fifth step, revealed that intended condom carrying was most likely to occur when people plan to buy condoms, experience social approval for condom carrying, are familiar with friends who regularly carry condoms, and finally, when they already are in the habit of carrying condoms (total $R^{2}=.70$ ).

\section{Behavior}

The regression analysis of actual condom carrying on possible antecedents revealed that condom carrying was more 
Table 4 Regression analyses of intended and actual condom carrying on condom carrying cognitions and preceding intentions and behavior $(N=$ 399)

\begin{tabular}{|c|c|c|c|c|c|c|c|c|}
\hline & \multicolumn{4}{|c|}{ Intended condom carrying } & \multicolumn{4}{|c|}{ Actual condom carrying (T2) } \\
\hline & $r$ & Initial Model $\beta$ & Final Model $\beta$ & $\Delta R^{2}$ & $r$ & Initial Model $\beta$ & Final Model $\beta$ & $\Delta R^{2}$ \\
\hline Step 1 & & & & $.085 * * *$ & & & & $.216 * * *$ \\
\hline \multicolumn{9}{|l|}{ \# of partners (referent: none) } \\
\hline One & .060 & .056 & .010 & & .071 & .082 & .019 & \\
\hline Two & .112 & .105 & -.028 & & .085 & .095 & -.031 & \\
\hline Three or more & .198 & $-.181 * *$ & -.056 & & .370 & $.333 * * *$ & .031 & \\
\hline Intentional abstinence & -.263 & $-.181 * *$ & .060 & & -.355 & $-.222 * * *$ & -.073 & \\
\hline Step 2 & & & & $.526 * * *$ & & & & $.232 * * *$ \\
\hline Intention to carry condoms & & - & - & & .353 & $.324 * * *$ & .073 & \\
\hline Intention to buy & .786 & $.764 * * *$ & $.683 * * *$ & & .251 & $-.210^{* *, \mathrm{a}}$ & -.095 & \\
\hline Intention to use condoms & .270 & .013 & .001 & & .018 & .005 & .002 & \\
\hline Buying (T2) & - & - & - & & .576 & $.454 * * *$ & $.414 * * *$ & \\
\hline Step 3-TPB variables & & & & $.033 * * *$ & & & & $.027 * *$ \\
\hline Attitudes & .381 & $.090^{*}$ & .028 & & .329 & $.121 *$ & .039 & \\
\hline Injunctive norm & .444 & $.141 * * *$ & $.093 *$ & & .311 & .079 & .067 & \\
\hline Self-efficacy & .355 & .033 & -.001 & & .306 & .060 & .013 & \\
\hline Step 4-Additional concepts & & & & $.013 * *$ & & & & .002 \\
\hline Descriptive norm & .352 & $.100 * *$ & $.073 *$ & & .303 & -.005 & -.035 & \\
\hline Personal norm & .228 & .009 & .012 & & .009 & -.048 & -.040 & \\
\hline Anticipated regret & -.063 & $-.075^{*, \mathrm{a}}$ & -.057 & & -.069 & .009 & .027 & \\
\hline Step 5 & & & & $.031 * * *$ & & & & $.100 * * *$ \\
\hline Habit & .468 & $.231 * * *$ & $.231 * * *$ & & .631 & $.437 * * *$ & $.437 * * *$ & \\
\hline Total $R^{2}$ & & & & .700 & & & & .575 \\
\hline
\end{tabular}

Note: $* p<.05, * * p<.01, * * * p<.001$

${ }^{\text {a }}$ Suppressor effect

likely to occur among participants who reported more frequent sexual activity. This relationship held after the second step, while intended carrying and actual condom buying explained additional variance. The negative beta weight of intended buying again suggests a suppressor effect: intended buying reduced the error variance in the relationship between intended carrying and actual carrying. ${ }^{5}$ The third step showed that attitude toward condom carrying had a direct effect on actual carrying, and was not fully mediated by intended condom carrying. The fourth step did not explain any significant additional variance, while the fifth step, in which habit was entered, did. Habit diminished the relationship of intended buying and carrying with actual carrying. The final model explained $58 \%$ of variance in condom carrying; the only significant predictors were buying condoms and the habit of carrying condoms.

\footnotetext{
5 The correlation between intended buying and intended carrying was high $(r=.79)$, suggesting possible multicollinearity and, as such, the outcome might be biased. The VIF and Tolerance scores, however, suggest that the bias might be limited (Tolerance $\geq .35$; VIF $<3$ ).
}

Differences Between Sexually Active and Inactive Adolescents

Finally, differences in psychosocial factors of condom use between sexually active $(n=146)$ and inactive adolescents $(n=251)$ were examined. Multivariate analyses, using a Bonferroni correction to adjust for multiple testing, revealed that, in general, there was agreement between the two groups with regard to cognitions of condom use with casual sex partners (see Table 5). The only differences were related to anticipated regret, with inexperienced adolescents anticipating more negative feelings when having had unprotected sexual intercourse. More specifically, when comparing participants without past sexual experience $(n=251)$ with participants who had had one partner $(n=46)$, two partners $(n=33)$, or three or more partners $(n=64),{ }^{6}$ only the three or more partners group differed from the other groups $(M$ 's difference ranged from 1.04 (1 partner) to 1.37 (2 partners), $p<.01)$.

\footnotetext{
${ }^{6}$ Of the people who reported ever having had sexual intercourse, four participants did not report the number of sex partners.
} 
For condom use with steady sex partners, differences existed with regard to attitudes, personal norms and anticipated regret, with inexperienced people reporting more favorable cognitions towards the use of condoms with steady sex partners. Again, differences were only related to the three or more partners group, which differed from the sexual inexperienced group in terms of attitudes $(M$ difference $=.94, p<.01)$ and personal norms $(M$ difference $=.72, p<.001)$, and from all other groups on anticipated regret $(M$ 's difference ranged from 1.08 (1 partner) to 1.53 (0 partners), $p<.05$ ).

When examining psychosocial factors of condom buying and condom carrying, a number of differences were found with regard to the preparatory behaviors. Experienced adolescents generally reported being more favorable to condom buying and condom carrying, as well as expressing a higher perceived capability of doing so. It should be noted that, when examining subgroups, almost all differences related to condom buying disappeared. The only difference was that the no partner group differed from the three or more partner group in terms of self-efficacy ( $M$ difference $=.77, p<.01$ ). For condom carrying, the sexual inexperienced group differed from adolescents with two or more partners, in terms of attitudes ( $M$ 's difference $\geq .97, p<.05$ ), injunctive norms ( $M$ 's difference $\geq .70, p<.05$ ) and self-efficacy ( $M$ 's difference $\geq .77, p<.05$ ). Additionally, the sexual inexperienced group differed from the three or more partners group in terms of descriptive norms $(M$ difference $=.86, p<.001)$.

\section{Discussion}

In the present study, we studied the sequence of steps that adolescents need to take to attain the goal of using condoms and their action-specific cognitions. The steps examined were: deciding to use condoms, buying condoms, and carrying condoms. We attempted to demonstrate that there was a logical sequence of steps and that simply focusing on intended condom use as the most proximal antecedent of condom use is not necessarily sufficient. We showed that having a positive intention to use condoms did not necessarily lead to buying and carrying condoms, the behaviors that have been shown to be very important in achieving condom use (Bryan et al., 2002; Sheeran, Orbell, \& Abraham, 1999; van Empelen \& Kok, 2006). In examining the sequence of steps, intended condom use did explain intended condom buying, but it did not predict actual buying. It could be argued that the relationship between intended condom use and buying was mediated by intended buying, but the zero-order correlations suggest that this was not the case. In turn, when we examined condom carrying, intended carrying largely depended on intended buying, and not on intended condom use. Moreover, in explaining actual condom carrying, it was shown that carrying condoms was

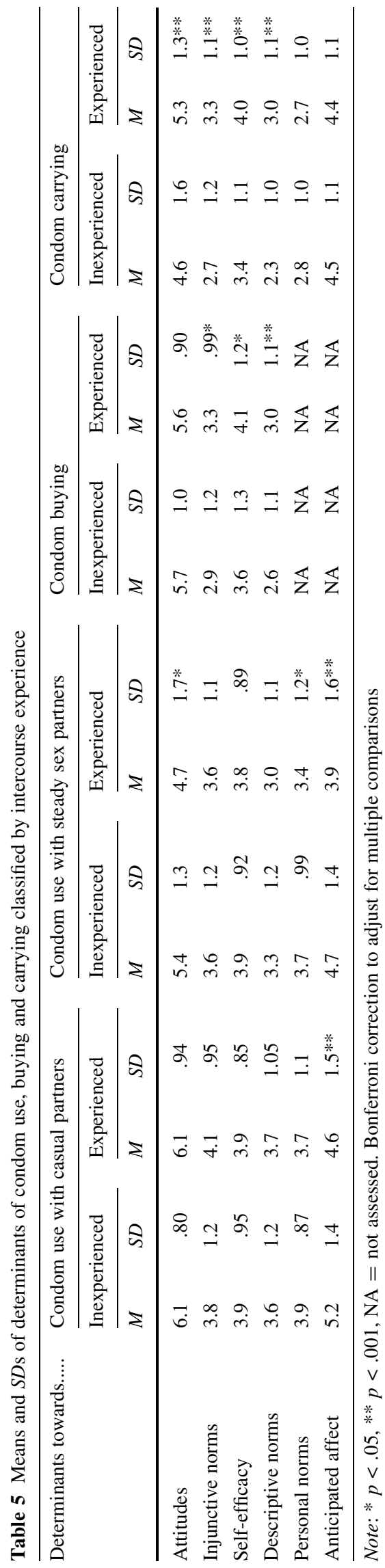


dependent on whether adolescents actually had bought condoms and intended to carry them. In sum, the results suggest that it is necessary to take into account specific preparatory actions, but that it is also essential to examine their specific cognitions (see Fig. 2 for a summarized model).

The results indicated that the TPB variables were important predictors of intended condom use. In addition, personal norms and anticipated affect appeared to be particularly important in the context of casual sex partners, which is clearly seen as a less desirable situation in which to engage in unprotected sex. Perceived social approval (i.e., injunctive and descriptive norms) seemed an important factor throughout all behavioral stages of condom use, especially with regard to (intended) preparatory behaviors. Injunctive norms were all indirectly affecting behaviors via intention, which is in line with the TPB. Similarly, descriptive norms affected behavior via intentions, except for condom buying, where descriptive norms were not related to intended buying, but instead predicted actual buying. In other words, descriptive norms can influence decision making, but may also lead directly to imitation, which is in line with SCT (Bandura, 1997). Additionally, attitude was found to have a direct effect on condom carrying, beyond intention. This direct relationship is in line with the literature, which suggests attitudes can activate behavior automatically, without intentional elaboration, when attitudes are highly accessible (Bargh, 1997; Fazio, 1986). Finally, habit was found to be a direct predictor of the preparatory behaviors and seems to overrule the effect of the cognitive factors. This also suggests that it is desirable to establish safer sexual behaviors early in the sexual careers of adolescents and to ensure safer sex habits are created.

Our approach of subdividing the goal of condom use into specific underlying behaviors concurs with the principle of

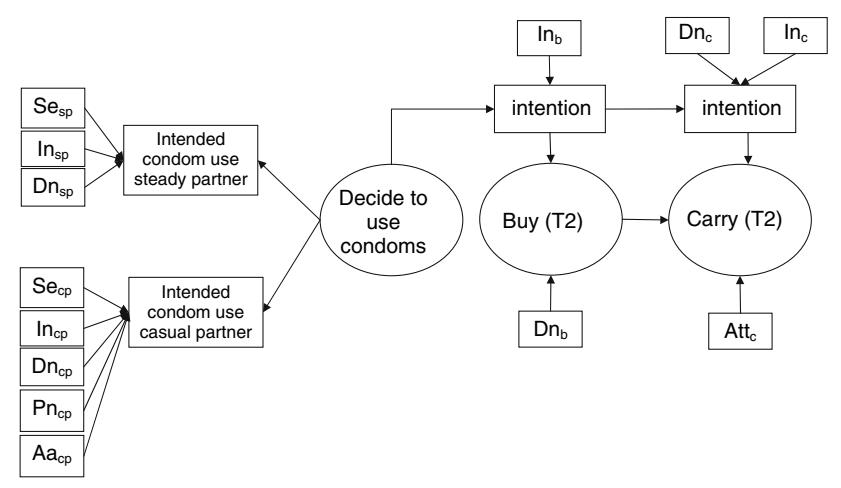

Fig. 2 Summarized model of condom preparatory actions. I = intention; Att = Attitude; In = injunctive norm; Se = self-efficacy; $\mathrm{Dn}=$ descriptive norm; $\mathrm{Pn}=$ Personal norm; $\mathrm{Aa}=$ Anticipated affect. Subscripts: $\mathrm{sp}=$ steady partner, $\mathrm{cp}=$ casual partner, $\mathrm{b}=$ condom buying, $\mathrm{c}=$ condom carrying compatibility (i.e., ensuring correspondence in measurement between cognitions and behaviors), as condom use may be considered a behavioral category rather than a single behavior (cf. Fishbein, 1993). By focusing on more specific behaviors, it is easier to examine important cognitions because it is more likely that those cognitions are also more salient when plans are formulated or executed, thereby providing important information for intervention development.

The study results also suggests that motivational issues may play a role in behaviors, beyond the decision to use condoms, which is in contrast with action-oriented models, such as the Health Action Process Approach model (Schwarzer, 1992) and the Rubicon Model of Action Phases (Gollwitzer, 1996), which suggest that once people are motivated to pursue a specific goal, the additional processes of goal attainment are volitional. Our study suggests that preparatory behaviors are not entirely volitional and adolescents need to be motivated to carry out the preparatory behaviors.

Intentional abstinence was largely mediated by other social-cognitive factors, except in regard to condom buying behavior. This seems logical, as people who are not open to sexual intercourse in the short term will not feel the need to buy condoms. However, six of the participants among those who reported to be inclined toward abstinence at baseline $(n=116)$, reported having a sex partner at follow-up, suggesting that the delay of onset of sexual activity to prevent HIV may be an important AIDS prevention tool, particularly for adolescents, but it may not be sufficient. Moreover, the abstinence approach has not found cogent empirical support (Jemmott \& Fry, 2002; Silva, 2002). Focusing solely on abstinence might not be appropriate for all adolescents, and it certainly does not prepare them for the sexual activity they most likely will experience eventually.

The impact of sexual experience seems limited with regard to differences in cognitions towards condom use with casual sex partners. In general, adolescents were favorable towards condom use with casual sex partners, regardless of their sexual experience. With respect to condom use in steady sexual relationships, sexually inexperienced adolescents were generally more favorable towards condom use than experienced adolescents (cf. Schaalma et al., 1993), although the differences were small. Thus, in general, adolescents did not seem to differ with regard to their opinions and beliefs about condom use, although a positive evaluation of condom use may decline with experience. This may suggest that preparing adolescents for possible negative consequences of using condoms is important in order to train them to cope with those consequences and to encourage condom maintenance.

Differences did exist with regard to preparatory actions for condom use, with sexually experienced adolescents being more positive and self-efficacious towards condom carrying and buying. It is important among sexually inexperienced 
adolescents to emphasize their generally positive cognitions about the use of condoms, and to stress that not anticipating possible sexual encounters may eventually compromise their own ideas about condom use. Furthermore, skill building to purchase or carry condoms may reduce resistance against buying or carrying condoms. Finally, it seems important for both sexually experienced and inexperienced adolescents to establish a sense of social approval of others, like peers and family members, for condom buying and carrying because this study showed that this is likely to be indirectly or directly related to preparatory actions.

We included other background factors (e.g., demographics) in the analyses, but most factors did not have a direct influence on any of the behaviors under examination. As such, it seems that possible differences are largely mediated by more proximal psychosocial factors, although it may well be that some factors may also moderate certain relationships between psychosocial factors and intended or actual behaviors (Van der Straten et al., 1998). One exception was the direct effect of gender on the buying of condoms, with girls less likely to buy condoms than boys.

In conclusion, it may be important to focus on the sequence of steps that need to be followed, and the underlying socialcognitive factors, in order to attain and even maintain a complex behavior such as condom use. Studies have shown that it is important to plan and prepare for certain behavior, such as condom use, and this may be especially important for adolescents, because of their sexual inexperience. Without specific planning and preparation, adolescents may engage in risky behavior simply because they find themselves in situations they had not anticipated (Gibbons et al., 2003; van Empelen \& Kok, 2006).

Before discussing the implications of the present study, it should be mentioned that the findings may be limited due to the fact that a large number of adolescents in the sample were sexually inexperienced. It is worth noting that the inclusion of inexperienced adolescents was done intentionally, given that most HIV prevention programs targeting adolescents, focus on ages at which the majority of adolescents is still inexperienced. Nevertheless, one may wonder to what extent a hypothetical condom use situation is related to real-life experience; more specifically, to what extent intentions are predictive of behavior, when the decision is hypothetical (e.g., Ajzen, Brown, \& Carvajal, 2004). Studies have shown that intentions were predictive in hypothetical situations of complex health behaviors and other behaviors (e.g., voting: Flynn et al., 1997). Moreover, intentions represent an individual's motivation and readiness for a specific goal behavior and as such are a very important prerequisite for behavior. Finally, the decision to engage in preparatory actions is not a hypothetical one. As such, such decisions may well explain the goal of condom use, over and above the behavioral intentions.
An additional limitation is related to the design of the study. Within the present study, we have suggested a chain of behaviors. Despite the two time measurements within the present study, some of the relationships examined were cross-sectional. Therefore, one could question the direction of the relationships. For instance, one may wonder to what extent the decision to use condoms leads to the decision to carry condoms or vice versa. Indeed, it is likely that both decisions have a bidirectional relationship. It is important that future studies further examine the causal chain of cognitions and behaviors, preferably by using cross-lagged panel designs, longitudinal or experimental designs in order to examine directionality and change.

School-based educational approaches can serve as important tools in disseminating information about HIV/ AIDS and preventive practices to adolescents, but also in teaching the behavioral skills needed for HIV preventive behavior (Kalichman \& Hospers, 1997). Moreover, they may be very effective in reaching those adolescents who are not yet sexually active. Kirby and DiClemente (1994) showed that the most effective school education programs had common characteristics: (1) a theoretical grounding in social learning or influence theories (e.g., Bandura, 1997); (2) a narrow focus on reducing specific sexual risk-taking behaviors; (3) experiential activities to convey information on the risks of unprotected sex, ways of avoiding those risks, and personalizing that information; (4) instruction on social influences and pressures; (5) reinforcement of individual values and group norms against unprotected sex that are ageand experience-appropriate; (6) activities aimed at increasing relevant skills and confidence (self-efficacy); and (7) special training for teachers and staff.

We contend that prevention programs should take into account the considerations of Kirby and DiClemente (1994), but should go beyond motivation-only approaches, by aiming at all planning and preparatory stages of goal achievement. Implementation plans (Gollwitzer, 1996) could be used as a means of reinforcing the initiation and frequency of engaging in preparatory behaviors among adolescents. Implementation intentions (that is, specifying when, where, and how the behavior is performed) may increase the frequency of preparatory behaviors because the contextual cues will elicit performance of the intended behavior. It should be noted, however, that this method requires that people possess a positive intention to perform a specific behavior. Thus, interventions should ensure that adolescents are motivated not only to use condoms, but also to buy and carry them. Additionally, peer education (e.g., Turner \& Shepherd, 1999) could be used as method to establish social approval with regard to preparatory behaviors, given that: (1) peers who prepare themselves (e.g., have condoms available) may function as positive role models, (2) peers are credible sources, (3) peers are reinforcing 
and empowering, and (4) peer models themselves may benefit from being a model. Furthermore, stimulating parent-child communication and parental control may create a sense of social approval, and both have shown to be related to a reduction in sexual risk taking, in terms of inconsistent condom use and inconsistent contraceptive use (e.g., Hutchinson, 2002; Wight, Williamson, \& Henderson, 2006). Finally, safer sexual behavior could be encouraged by ensuring that condoms are routinely available. Condom availability programs might enable adolescents to buy condoms, and may reinforce condom carrying, without necessarily increasing sexual activity (Kirby, 2002). Parents could also provide their children with condoms, to set a safe sex and condom availability norm, and to ensure that their children are well-prepared for safer sex.

Acknowledgement This research was supported by a Grant from The Netherlands Organization for Health Research and Development (ZonMw, Project No. 40050001). We thank Emma Massey for her suggestions with regard to English grammar and spelling.

Open Access This article is distributed under the terms of the Creative Commons Attribution Noncommercial License which permits any noncommercial use, distribution, and reproduction in any medium, provided the original author(s) and source are credited.

\section{References}

Abraham, C., \& Sheeran, P. (2003a). Acting on intentions: The role of anticipated regret. British Journal of Social Psychology, 42, 495-511.

Abraham, C., \& Sheeran, P. (2003b). Implications of goal theories for the theories of reasoned action and planned behaviour. Current Psychology, 22, 264-280.

Abraham, C., Sheeran, P., \& Johnston, M. (1998). From health beliefs to self-regulation: Theoretical advances in the psychology of action control. Psychology \& Health, 13, 569-591.

Abraham, C., Sheeran, P., Norman, P., Conner, M., De Vries, N., \& Otten, W. (1999). When good intentions are not enough: Modeling postdecisional cognitive correlates of condom use. Journal of Applied Social Psychology, 29, 2591-2612.

Ajzen, I. (1988). Attitudes, personality, and behaviour. Milton Keynes, England: Open University Press.

Ajzen, I. (1991). The theory of planned behavior. Organizational Behavior and Human Decision Processes, 50, 179-211.

Ajzen, I. (2002). Residual effects of past on later behavior: Habituation and reasoned action perspectives. Personality and Social Psychology Review, 6, 107-122.

Ajzen, I., Brown, T. C., \& Carvajal, F. (2004). Explaining the discrepancy between intentions and actions: The case of hypothetical bias in contingent valuation. Personality and Social Psychology Bulletin, 30, 1108-1121.

Ariely, D., \& Loewenstein, G. (2006). The heat of the moment: The effect of sexual arousal on sexual decision making. Journal of Behavioral Decision Making, 19, 87-98.

Bagozzi, R. P., Dholakia, U. M., \& Basuroy, S. (2003). How effortful decisions get enacted: The motivating role of decision processes, desires, and anticipated emotions. Journal of Behavioral Decision Making, 16, 273-295.

Bandura, A. (1997). Self-efficacy: The exercise of control. New York: Freeman.
Bakker, F., \& Vanwesenbeeck, I. (2002). Veilig vrijen en condoomgebruik bij jongeren en jong-volwassenen. Stand van zaken september 2002 en ontwikkelingen sinds april 1987 [Safe sex and condom use among youth and young adults]. Utrecht: Rutgers Nisso Groep.

Bargh, J. A. (1997). The automaticity of everyday life. In R. S. Wyer (Ed.), Advances in social cognition (Vol. 10, pp. 1-62). Mahwah, NJ: Erlbaum.

Bartholomew, L. K., Parcel, G. S., Kok, G., \& Gottlieb, N. H. (2006). Planning health promotion programs: An intervention mapping approach. San Francisco, CA: Jossey-Bass.

Bryan, A., Fisher, J. D., \& Fisher, W. A. (2002). Tests of the mediational role of preparatory safer sexual behavior in the context of the theory of planned behavior. Health Psychology, 21, 71-80.

Centers for Disease Control and Prevention. (2005). Trends in reportable sexually transmitted diseases in the United States, 2005. Atlanta, GA: Department of Health and Human Services, Centers for Disease Control and Prevention.

Conner, M., \& Flesch, D. (2001). Having casual sex: Additive and interactive effects of alcohol and condom availability on the determinants of intentions. Journal of Social Psychology, 31, 89-112.

Conner, M., \& Norman, P. (1996). Body weight and shape control: Examining component behaviours. Appetite, 27, 135-150.

de Graaf, H., Meijer, S., Poelman, J., \& Vanwesenbeeck, I. (2005). Seks onder je 25e. Seksuele gezondheid van jongeren in Nederland anno 2005 [Sex under 25: Sexual health of youth in The Netherlands]. Utrecht, The Netherlands: Rutgers Nisso Groep.

Dilorio, C., Maibach, E., O'Leary, A., Sanderson, C. A., \& Celentano, D. (1997). Measurement of condom use self-efficacy and outcome expectancies in a geographically diverse group of STD patients. AIDS Education and Prevention, 9, 1-13.

Fazio, R. H. (1986). How do attitudes guide behavior? In R. M. Sorrentino \& E. T. Higgins (Eds.), Handbook of motivation and cognition: Foundations of social behavior (pp. 204-243). New York: Guilford Press.

Fishbein, M. (1993). Introduction. In D. J. Terry, C. Gallois, \& M. McCamish (Eds.), The theory of reasoned action: Its application to AIDS-preventive behaviour (pp. $\mathrm{xv}-\mathrm{xxv}$ ). Oxford: Pergamon.

Flynn, B. S., Dana, G. S., Goldstein, A. O., Bauman, K. E., Cohen, J. E., Gottlieb, N. H., et al. (1997). State legislators' intentions to vote and subsequent votes on tobacco control legislation. Health Psychology, 16, 401-404.

Fortenberry, J., Tu, W., Harezlak, J., Katz, B. P., \& Orr, D. P. (2002). Condom use as a function of time in new and established adolescent sexual relationships. American Journal of Public Health, 92, 211-213.

Gibbons, F. X., Gerrard, M., Blanton, H., \& Russell, D. W. (1998). Reasoned action and social reaction: Willingness and intention as independent predictors of health risk. Journal of Personality and Social Psychology, 74, 1164-1180.

Gibbons, F. X., Gerrard, M., \& Lane, D. J. (2003). A social reaction model of adolescent health risk. In J. Suls \& K. A. Wallston (Eds.), Social psychological foundations of health and illness (pp. 107-136). Malden, MA: Blackwell Publishing.

Gollwitzer, P. M. (1996). The volitional benefits of planning. In P. M. Gollwitzer \& J. A. Bargh (Eds.), The psychology of action (pp. 287-312). New York: Guilford Press.

Hutchinson, M. K. (2002). The influence of sexual risk communication between parents and daughters on sexual risk behaviors. Family Relations, 51, 238-247.

Jemmott, J. B., \& Fry, D. (2002). The abstinence strategy for reducing sexual risk behavior. In A. O'Leary (Ed.), Beyond condoms: Alternative approaches to HIV prevention (pp. 109-137). New York: Kluwer Academic/Plenum Publishers. 
Kalichman, S., \& Hospers, H. J. (1997). Efficacy of behavioral skills enhancement. AIDS, 11, S191-S199.

Kirby, D. (2002). The impact of schools and school programs upon adolescent sexual behavior. Journal of Sex Research, 39, 27-33.

Kirby, D., \& DiClemente, R. J. (1994). School-based interventions to prevent unprotected sex and HIV among adolescents. In R. J. DiClemente \& J. L. Peterson (Eds.), Preventing AIDS: Theories and methods of behavioral interventions (pp. 117-139). New York: Plenum Press.

Kok, G., Schaalma, H. P., Ruiter, R. A. C., van Empelen, P., \& Brug, J. (2004). Intervention Mapping: A protocol for applying health psychology theory to prevention programmes. Journal of Health Psychology, 9, 85-98.

Morrison, D. M., Baker, S. A., \& Gillmore, M. R. (2000). Using the theory of reasoned action to predict condom use among high-risk heterosexual teens. In P. Norman, C. Abraham, \& M. Conner (Eds.), Understanding and changing health behaviour: From health beliefs to self-regulation (pp. 27-49). Amsterdam: Harwood Academic Publishers.

NIPO. (2002). Schoolverzuim in het Voortgezet Onderwijs [School absenteeism in secondary education]. Amsterdam: NIPO.

Orbell, S., Blair, C., Sherlock, K., \& Conner, M. (2001). The theory of planned behavior and ecstasy use: Roles for habit and perceived control over taking versus obtaining substances. Journal of Applied Social Psychology, 31, 31-47.

Ouellette, J. A., \& Wood, W. (1998). Habit and intention in everyday life: The multiple processes by which past behavior predicts future behavior. Psychological Bulletin, 124, 54-74.

Paul, E. L., McManus, B., \& Hayes, A. (2000). "Hookups": Characteristics and correlates of college students' spontaneous and anonymous sexual experiences. Journal of Sex Research, 37, $76-88$.

Perugini, M., \& Bagozzi, R. P. (2001). The role of desires and anticipated emotions in goal-directed behaviors: broadening and deepening the theory of planned behavior. British Journal of Social Psychology, 40, 79-98.

Richard, R., Van der Pligt, J., \& De Vries, N. (1995). Anticipated affective reactions and prevention of AIDS. British Journal of Social Psychology, 34, 9-21.

Schaalma, H., Kok, G., \& Peters, L. (1993). Determinants of consistent condom use by adolescents: The impact of experience of sexual intercourse. Health Education Research, 8, 255-269.

Schaalma, H. P., Abraham, C., Gillmore, M. R., \& Kok, G. (2004). Sex education as health promotion: What does it take? Archives of Sexual Behavior, 33, 259-269.

Schwarzer, R. (1992). Self-efficacy in the adoption and maintenance of health behaviors: Theoretical approaches and a new model. In R. Schwarzer (Ed.), Self-efficacy: Thought control of action (pp. 217-243). Washington, DC: Hemisphere Publishing Corporation.

Schwarzer, R., \& Renner, B. (2000). Social-cognitive predictors of health behavior: Action self-efficacy and coping self-efficacy. Health Psychology, 19, 487-495.

Sheeran, P., Orbell, S., \& Abraham, C. (1999). Psychosocial correlates of heterosexual condom use: A meta-analysis. Psychological Bulletin, 125, 90-132.

Silva, M. (2002). The effectiveness of school-based sex education programs in the promotion of abstinent behavior: A metaanalysis. Health Education Research, 17, 471-481.
Tabachnick, B. G., \& Fidell, L. S. (1996). Using multivariate statistics (3rd ed.). New York: Harper Collins.

Terry, D. J., Hogg, M. A., \& White, K. M. (1999). The theory of planned behaviour: Self identity, social identity and group norms. British Journal of Social Psychology, 28, 225-244.

Turner, G., \& Shepherd, J. (1999). A method in search of a theory: Peer education and health promotion. Health Education Research, 14, 235-247.

van de Laar, M. J. W., De Boer, I. M., Koedijk, F. D. H., \& Op de Coul, E. L. M. (2005). HIV and sexually transmitted infections in the Netherlands in 2004. An update: November 2005. RIVM rapport 441100022. Bilthoven: Rijksinstituut voor Volksgezondheid en Milieuhygiëne.

Van der Straten, A., Catania, J. A., \& Pollack, L. (1998). Psychosocial correlates of health-protective sexual communication with new sexual partners: The National Aids Behavioral Survey. AIDS and Behavior, 2, 213-227.

van Empelen, P., \& Kok, G. (2005). Reasons for young people to buy, carry, communicate about and use condoms. Unpublished raw data.

van Empelen, P., \& Kok, G. (2006). Condom use in steady and casual sexual relationships: Planning, preparation and willingness to take risks among adolescents. Psychology \& Health, 21, 165-181.

van Empelen, P., Kok, G., Jansen, M. W. J., \& Hoebe, C. J. P. A. (2001). The additional value of anticipated regret and psychopathology in explaining intended condom use among drug users. AIDS Care, 13, 309-318.

van Empelen, P., Schaalma, H. P., Kok, G., \& Jansen, M. W. J. (2001). Predicting condom use with casual and steady sex partners among drug users. Health Education Research, 16, 293-306.

van Kesteren, N. M. C., Hospers, H. J., van Empelen, P., van Breukelen, G., \& Kok, G. (2007). Sexual-decision making in HIV-positive men who have sex with men: How moral concerns and sexual motives guide intended condom use with steady and casual sex partners. Archives of Sexual Behavior, 36, 437-449.

Vanwesenbeeck, I., Bakker, F., van Fulpen, M., Paulussen, T., Poelman, J., \& Schaalma, H. (2003). Seks en seksuele risico's bij VMBO-scholieren anno 2002 [Sex and sexual risks among secondary school pupils in 2002]. Tijdschrift voor Seksuologie, 27, 30-39.

Verplanken, B., \& Orbell, S. (2003). Reflections on past behavior: A self-report index of habit strength. Journal of Applied Social Psychology, 33, 1313-1330.

Webb, T. L., \& Sheeran, P. (2006). Does changing behavioral intentions engender behavior change? A meta-analysis of the experimental evidence. Psychological Bulletin, 132, 249-268.

Wight, D., Williamson, L., \& Henderson, M. (2006). Parental influences on young people's sexual behavior: A longitudinal analysis. Journal of Adolescence, 29(4), 473-494.

White, K. M., Terry, D. J., \& Hogg, D. A. (1994). Safer sex behavior: The role of attitudes, norms, and control factors. Journal of Applied Social Psychology, 24, 2164-2192.

Yzer, M. C., Siero, F. W., \& Buunk, B. P. (2001). Bringing up condom use and using condoms with sexual partners: Intentional or habitual? Psychology \& Health, 16, 409-421. 